significance from the point of view of allergy, as hair-nets are more often worn by older women, and relatively seldom by younger women with short hair styles.

The duration of the sensitivity when first seen varied from three weeks to seven years. Most patients gave a history of some months. One must admit, however, that a number of cases were not diagnosed for long periods after their first attendance at hospital.

There was no evidence of an atopic diathesis; none had had atopic eczema, and only one patient had hay-fever.

\section{Patch Tests}

All the patients except one were patch-test positive to the nylon portion of the hair-net. The one exception (Case 24) was allergic to the rubber of the elastic band but not to the nylon. When patch testing with the rubber, one must take great care to remove all trace of the nylon thread, which is usually wound round the elastic.

In our cases, hair-net sensitivity from the nylon part was always attributable to the dye, and patch tests usually gave an acute vesicular reaction at 48 hours. A single case gave a negative reaction at 48 hours, but was positive when read 48 hours later.

No routine cross-sensitivity tests with the "para " group were done, but patients were tested with any substances which were suspected of causing their other patches of dermatitis. The results are shown in Table I. It can be seen that 11 patients $(40 \%)$ showed cross-sensitivity dermatitis-a striking illustration of the importance of this phenomenon. Not all patients reacted to chemically related substances, and five cases showed additional unrelated sensitivities.

It is extremely difficult, if not impossible, to trace the precise dye used in a particular patient's hair-net. We have reason to suppose that they are usually azo-dyes, of which there are a large variety. We have patch-tested a number of our patients with paraphenylenediamine, and a red, yellow, and blue azo-dye, and the results are shown in Table IV.

\begin{tabular}{|c|c|c|c|c|}
\hline \multirow{2}{*}{ Case No. } & \multirow{2}{*}{$\begin{array}{l}\text { Paraphenyl- } \\
\text { enediamine }\end{array}$} & \multicolumn{3}{|c|}{ Azo Dyes } \\
\hline & & Red & Blue & Yollow \\
\hline $\begin{array}{r}1 \\
2 \\
4 \\
6 \\
7 \\
8 \\
9 \\
10 \\
11 \\
12 \\
13 \\
14 \\
15 \\
16 \\
17 \\
18 \\
19 \\
20 \\
21 \\
22 \\
23 \\
25 \\
26 \\
27\end{array}$ & $\begin{array}{l}+ \\
+ \\
+ \\
+ \\
\pm \\
\pm \\
\\
+ \\
+ \\
+ \\
+ \\
+ \\
+ \\
+ \\
+ \\
+ \\
+ \\
+ \\
+ \\
\pm\end{array}$ & $\begin{array}{l} \pm \\
\pm \\
\pm \\
+ \\
\pm \\
\pm \\
- \\
- \\
\pm \\
+ \\
+ \\
+ \\
\pm \\
\pm \\
+ \\
+\end{array}$ & $\begin{array}{l} \pm \\
= \\
+ \\
= \\
= \\
- \\
=\quad . \\
= \\
\pm \\
\pm \\
\pm \\
\pm \\
\pm\end{array}$ & $\begin{array}{c}++ \\
++ \\
+ \\
+ \\
++ \\
++ \\
+ \\
+ \\
- \\
- \\
+ \\
+ \\
+ \\
++ \\
++ \\
+ \\
\pm \\
+ \\
++ \\
++\end{array}$ \\
\hline
\end{tabular}

These particular chemicals are employed in dyeing nylon stockings, but we have no proof that these were the actual dyes used on the hair-nets worn by any of our patients.

\section{Discussion}

The fact that we have been able to collect 27 cases within 18 months suggests that this is not a rare condition, and we think it likely that many cases go undiagnosed. The rash produced by sensitivity to nylon hair-nets so closely resembles one of constitutional origin that several of our cases were incorrectly diagnosed when first seen. In spite of increased experience we cannot always distinguish the two conditions by clinical examination alone, and it is essential that every patient presenting an eczematous rash of this pattern should be asked if she wears a nylon hair-net. If she does so, she should be patch-tested against it. The fact that a patient can wear nylon stockings with impunity does not necessarily invalidate the diagnosis, as many of our patients were able to wear nylon stockings without getting a rash. Even those who did develop a stocking dermatitis did not do so until several months after the onset of their hair-net dermatitis.

One of our cases was sensitive to the rubber band, while the remainder gave positive patch tests to the material of their hair-nets. When tested against a routine batch of azodyes used for dyeing stockings, they gave positive reactions, usually to the yellow or red, but occasionally to the blue dye. Although we were unable to obtain the actual dyes used on the nets, we consider that hair-net dermatitis results from sensitivity to the dye in the majority of cases. When the nylon net was discarded, even if replaced by a silk or hair one, the rash cleared. The skin returned to normal after an interval varying from a few weeks to several months.

\section{Summary}

Twenty-seven cases of nylon hair-net dermatitis are reported.

Although closely resembling that of seborrhoeic eczema, the uncomplicated rash has a characteristic pattern.

With one exception, sensitivity to the dye appeared to be responsible.

We thank all members of the staff of St. John's Hospital for Diseases of the Skin who referred cases to us; also Dr. Sydney Thomson and Dr. David Williams for allowing us to investigate their cases.

REFERENCES

Anderson, C. R. (1950). Arch. Derm. Syph. (Chicago), 61, 111.

. 40, 224.

Beck, G. A. (1957). Trans. St John's Hosp. derm. Soc. (Lond.), No. 38 p. 37.

C. D. (1956). Brit. J. Derm., 68, 229

- (1957a). Trans. St John's Hosp. Derm. Soc. (Lond.), No. 39, p. 75.

- and Sarkany, I. (1957). Ibid., No. 39, p. 28

- and Wilson, H. T. H. (1956). Brit. med. J., 1, 147

\section{SUCCESSFUL TWIN PREGNANCY AFTER TREATMENT OF MALIGNANT ESSENTIAL HYPERTENSION}

\author{
BY
}

\author{
JOHN H. ROSS, M.B., M.R.C.P., D.Obst.R.C.O.G \\ Senior Registrar, London Hospital \\ AND \\ JOHN A. WRIGHT, M.B., B.S. \\ Senior Resident Accoucheur, London Hospital
}

The benefits resulting from the introduction of lumbodorsal sympathectomy and hypotensive drugs in the treatment of malignant essential hypertension are well recognized (Northfield, 1948 ; Smithwick, 1951 ; Rosenheim, 1954 ; Smirk, 1954 ; Smirk, Doyle, and McQueen, 1954 ; Pickering, 1955). It is, however, often impossible or impracticable to maintain the blood pressure at normal levels in some patients following one or other of these methods of treatment, although hypertensive symptoms may be relieved, papilloedema may resolve, and progressive renal damage may be arrested. Such patients then resemble those with benign essential hypertension; they may remain free from symptoms, but are still apt to develop cerebrovascular or cardiac complications. In addition, women of childbearing age may suffer the risks of hypertensive pregnancy. 
The following report describes a case of malignant essential hypertension first treated by sympathectomy. Hypertension, persisting after sympathectomy, was then controlled with hypotensive drugs and the blood pressure was maintained within normal limits during the greater part of a successful twin pregnancy.

\section{Case Report}

A married woman aged 27 was admitted to the Dorset County Hospital in January, 1954, complaining of blurring of vision and retro-orbital pain in the left eye for a few days. She gave no past or family history of renal disease. She was found to have gross bilateral papilloedema with exudates and flame-shaped haemorrhages, more marked in the left retina. Her blood pressure was $260 / 200 \mathrm{~mm}$. Hg. A diagnosis of malignant hypertension was made, and after treatment with rest in bed and hexamethonium bromide all her symptoms resolved, her blood pressure fell to $200 / 130$, and she was discharged in March.

In April she was admitted to the London Hospital. At that time she was still taking oral hexamethonium bromide. Her blood pressure was $280 / 150$ and there was bilateral papilloedema with retinal exudates, but no haemorrhages. A few discrete enlarged lymph nodes in both posterior cervical triangles and a palpable tip of spleen were also noted.

Investigations on admission gave the following results. $\mathrm{Hb}, 85 \%$ (12.6 g. per $100 \mathrm{ml}$.) ; E.S.R., $6 \mathrm{~mm}$. in one hour ; blood urea, $39 \mathrm{mg}$. per $100 \mathrm{ml}$. Maximum urine urea concentration, $2.88 \mathrm{~g}$. per $100 \mathrm{ml}$. Catheter specimen of urine: cloud of protein but no casts or excess red cells. Intravenous pyelography and perirenal insufflation of oxygen showed normal excretion of dye and normal renal and adrenal outlines. Excretion of noradrenaline in a 24-hour specimen of urine was normal. Chest $x$-ray examination showed normal-sized heart and no pulmonary lesion. The diagnosis was essential hypertension in the malignant phase.

During the next few weeks further enlargement of the cervical glands and spleen was noted, but she remained asymptomatic and apyrexial. Repeated blood counts and chest $x$-ray films were normal and her blood Wassermann reaction was negative. A cervical gland biopsy showed reticulum-celled hyperplasia with a slight increase of plasma cells and focal fibrosis. This was thought to be probably due to chronic inflammation, but a reticulosis could not be excluded. The glands have since decreased in size and the spleen has only occasionally been felt. With rest in bed and oral hexamethonium bromide her blood pressure varied betwen $160 / 110$ and 230/160 in the supine position. The response to treatment was not considered satisfactory, and in July and August, 1954, bilateral thoracolumbar sympathectomy (T 5 to L 3) and splanchnicectomy was performed. Before operation her blood pressure varied between $210 / 150$ and $270 / 220$. After operation there was only a slight fall in her blood pressure, and three months later it was $195 / 110$ in the supine position. A biopsy of the right kidney at the time of operation showed medial hypertrophy of all arterioles with marked subintimal hyalinization but no fibrinoid necrosis. Of 28 glomeruli, six were completely hyalinized, six had shrunken tufts with marked capsular fibrosis, and the remainder showed focal necroses and capsular adhesions. There was focal collagenous increase in the interstitial tissue with patchy tubular atrophy. These changes were thought to be the result of hypertension rather than of primary renal disease.

During the next two years she received no hypotensive therapy and remained well apart from slight shortness of breath on exertion and an occasional frontal headache when fatigued. She worked as a full-time schoolteacher. She wanted children, but was advised against pregnancy. On her annual visits to the London Hospital out-patient department her blood pressure was about 210/130 with a slight postural fall. A cloud of protein persisted in her urine. The optic disk edges remained blurred and the physiological cups could not be seen, but the papilloedema had resolved. The retinal arteries remained tortuous, and many new vessels appeared around the disk margins. Haemorrhages and exudates were no longer to be seen (see Fig.).

In November, 1956, at her annual visit to the out-patient department, she thought she was two months pregnant (L.M.P. September 18 ; E.D.D. June 25, 1957). A 24-hour rat pregnancy test was positive, and she was admitted for consideration of termination of pregnancy. On examination her blood pressure was $220 / 135$ in the supine position. The fundi were unchanged and her visual acuity was (R) $6 / 5$ and $(\mathrm{L}) 6 / 6$. Her urine still contained a cloud of protein.

Investigations in December, 1956, showed: $\mathrm{Hb}, 92 \%$ (13.6 g. per $100 \mathrm{ml}$.) ; blood urea, $36 \mathrm{mg}$. per $100 \mathrm{ml}$.; maximum urine urea concentration, 1.5 g. per 100 ml. ; E.C.G. left axis deviation. Chest $x$-ray examination showed no cardiac enlargement.

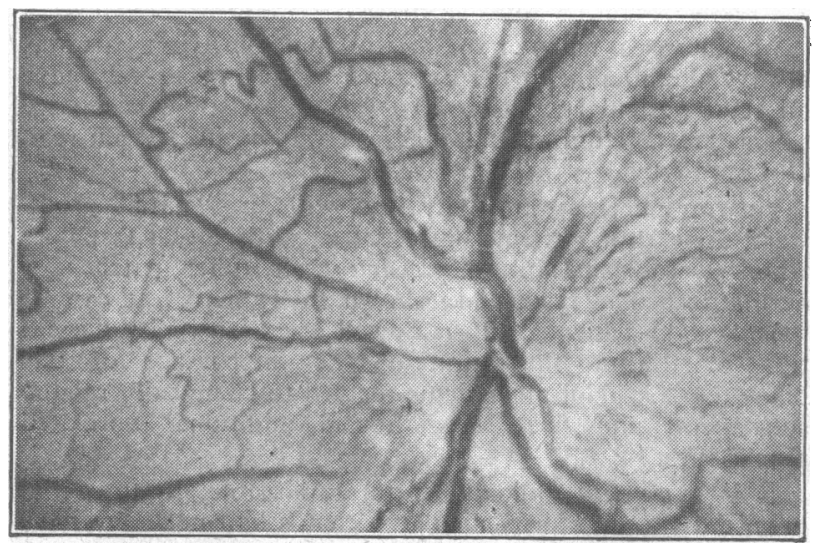

Right optic fundus, March 19, 1957. Optic disk flat, but edges blurred and physiological cup not visible. Many new tortuous vessels around the disk margins.

It was considered that the chances of a live birth were small and that there was a risk of further hypertensive damage if the pregnancy was allowed to continue ; termination was therefore recommended. However, the patient and her husband were both keen to allow pregnancy to continue with a trial of hypotensive therapy. It was finally decided that termination in a symptomless and reluctant patient might have an adverse psychological effect, and, as the results of strict hypotensive therapy in pregnancy were not yet clearly established, she was allowed to continue under careful supervision.

She began treatment (12 weeks pregnant) with reserpine, $0.25 \mathrm{mg}$. three times a day, mecamylamine, $1.25 \mathrm{mg}$. four times a day, and phenobarbitone, $\frac{1}{2}$ gr. $(32 \mathrm{mg}$.) twice a day. No salt was added to her food and she was at rest most of the day. Within a few days her urine became free of protein and it remained so throughout her pregnancy. Her blood pressure fell, and during the next month it remained at about $139 / 95$ when supine and $130 / 80$ when standing. The highest levels recorded were $190 / 120$ when supine and $160 / 110$ when standing. In January, 1957, she was discharged from hospital on the same treatment. At 18 weeks her uterus was noted to be unduly large, and radiography confirmed twin pregnancy. During the following weeks her weight rose excessively and her blood pressure slightly. In February (22 weeks) her blood pressure was $160 / 100$ when supine and 140/100 on standing. The dose of mecamylamine was increased to $2.5 \mathrm{mg}$. three times a day. However, there was no significant fall in her blood pressure, and in March (26 weeks) she was readmitted for observation. During the next 10 weeks she was allowed out of bed for toilet purposes only. She remained well apart from minimal dyspnoea and very occasional hypotensive symptoms on standing. Her blood pressure fluctuated considerably, but was usually about $135 / 90$ when supine and 120/80 when standing. The highest levels recorded were $200 / 140$ when supine and 170/110 when standing. Her weight gain was 
not excessive, and an increase of $32 \mathrm{lb}$. $(14.5 \mathrm{~kg}$.) from the eleventh to the thirty-sixth week was regarded as normal for a twin pregnancy. There was no oedema and her blood urea remained normal. Lower-segment caesarean section at about 36 weeks was contemplated, and at 34 weeks an $x$-ray examination of the abdomen was made to estimate the foetal size and maturity. This showed both foetuses to be presenting by the vertex, with the placenta situated in the upper posterior part of the uterine wall. The absence of any lower femoral epiphyses suggested that the foetuses were not more than 36 weeks at the maximum.

At the 36th week of pregnancy (May, 1957) the membranes ruptured spontaneously. Following a first stage of four hours' duration, during which the patient had no pain, two live female infants were delivered by forceps under general anaesthesia (nitrous oxide, oxygen, trichlorethylene, and ether). A normal third stage followed, with the delivery of a healthy binovular placenta. The first twin, weighing 3 lb. 2 oz. (1,430 g.), cried spontaneously at birth and was of good tone and colour. The second twin, weighing $4 \mathrm{lb} .6 \mathrm{oz}$. $(1,985 \mathrm{~g}$.), showed marked blue asphyxia at birth, with little response to pharyngeal suction, intragastric oxygen, and intravenous nalorphine hydrobromide. Normal respiration was finally established some 20 minutes after delivery following intubation and aspiration under direct vision, combined with artificial respiration. During the puerperium, trials were first made with mecamylamine, $2.5 \mathrm{mg}$. three times a day, and reserpine $0.25 \mathrm{mg}$. twice a day, separately. Neither produced a sustained fall in blood pressure, and in the fifth week mecamylamine, $2.5 \mathrm{mg}$. twice a day, was combined with reserpine, $0.25 \mathrm{mg}$. twice a day, and her blood pressure dropped to a steady level of about $150 / 100$ when supine. In the third week of the puerperium her blood urea was $30 \mathrm{mg}$. per $100 \mathrm{ml}$, maximum urine urea concentration $1.27 \mathrm{~g}$. per $100 \mathrm{ml}$., and creatinine clearance $81 \mathrm{ml}$. per minute. She remained asymptomatic, gradually increasing her activities until she was up throughout the day breast-feeding and caring fully for her twins. Both infants thrived; after a short period of tube feeding they were later breast-fed on demand. On discharge from hospital, aged 6 weeks, the first twin weighed $4 \mathrm{lb} .11 \mathrm{oz}$. $(2,125 \mathrm{~g}$.) and the second $5 \mathrm{lb} .11 \mathrm{oz}$. $(2,580 \mathrm{~g}$.$) .$

\section{Discussion}

Pregnancy in patients with essential hypertension in the malignant phase is rare, and before satisfactory treatment was introduced termination was always recommended (Fishberg, 1954). There is no record of a successful pregnancy in an untreated patient. There have been several reports of pregnancies following sympathectomy. Newell and Smithwick (1947) reported 14 cases, three of which had had malignant hypertension. Two of these were described as having pyelonephritis also. The blood pressure was only slightly raised at the onset of their pregnancies, which occurred nine months, one year, and four and a half years after sympathectomy. One of these pregnancies was uneventful; one patient had no rise in blood pressure during pregnancy, which was terminated by caesarean section ; and one had a surgical induction at the 38th week following increasing hypertension and proteinuria.

Peet (1948) reported 34 pregnancies in 28 women following sympathectomy. None are described as having had malignant hypertension. Eighteen had maintained normal blood pressure levels after operation and before pregnancy, and 17 of these gave birth to 18 living infants. Of the 10 remaining patients whose blood pressure had not been reduced to normal, only two were delivered of living infants at full term.

d'Abreu (1953) described four cases of successful pregnancy after sympathectomy. Again none had hypertension in the malignant phase prior to operation.

The use in pregnancy of hypotensive drugs, including mecamylamine and pentolinium tartrate with or without rauwolfia alkaloids, has not yet been adequately reviewed. Hexamethonium and pentolinium tartrate are perhaps more effective in the treatment of pre-existing hypertension in pregnancy than of "toxaemic" hypertension (Morris, 1953 ; Blair, 1954; Townsend, 1955). Hydrallazine hydrochloride should theoretically have special value as a hypotensive agent, since it increases renal blood flow, but it has a toxic effect resembling disseminated lupus erythematosus (Morrow, Schroeder, and Perry, 1953). Veratrum alkaloids have been shown to produce acute reduction of blood pressure and to improve the outlook for the mother more than the child in the presence of "toxaemia" (Morris, 1955).

The risks to mother and foetus in pregnancy when there is pre-existing hypertension are well known; but the longterm effect on blood pressure of pregnancy in such cases is still not clearly defined (Browne, 1947; Chesley and Annitto, 1947 ; Chesley, Annitto, and Jarvis, 1947). Multiple pregnancies are known to predispose to hypertensive "toxaemia" more frequently than single pregnancies (Brews, 1953). Our patient risked complications in pregnancy due to pre-existing hypertension, and her chances of an added "toxaemia" were increased by the twin foetuses. It cannot, however, be claimed that the treatment during pregnancy prevented additional "toxaemia," the development of which is unpredictable in any individual patient.

The ease of maintenance of normal levels of blood pressure in this patient with small doses of mecamylamine and reserpine was striking. This successful combination of sympathectomy with hypotensive drugs has been observed by one of us (J. H. R.) in other patients. Although sympathectomy for severe hypertension has been employed less in recent years, it still has a place in the treatment of patients with malignant essential hypertension in whom large doses of hypotensive drugs are ineffective or produce severe sideeffects but who are fit enough to withstand the operation. If necessary, smaller doses of the drugs may be tried afterwards.

The neonatal asphyxia of the second twin was probably not related to the mother's treatment, and it would appear that the hypotensive drugs had no ill effects on the infants (their blood pressures were not recorded). It has been observed that hexamethonium passes freely into the amniotic fluid, and swallowing of the fluid has been suggested as being responsible for neonatal deaths by Morris (1953), who described the treatment of 26 pregnant women with hypertension. There were 7 stillbirths and 19 live births, with 7 neonatal deaths (within eight days). There is no information available yet about the tranşference of mecamylamine across the placenta.

\section{Summary}

A successful twin pregnancy 33 months after the mother had undergone bilateral thoracolumbar sympathectomy for malignant hypertension is described. Hypertension persisting after the operation was controlled with mecamylamine and reserpine.

We thank Lord Evans and Mr. Alan Brews, under whose care this patient was treated at the London Hospital, and Professor Clifford Wilson for their help in the preparation of this paper.

\section{REFERENCES}

Blair, B. (1954). J. Obstet. Gynaec. Brit. Emp., 61, 505

Brews, A. (1953). In Eden and Holland's Manual of Obstetrics, 10th ed. London.

Browne, F. J. (1947). Brit. med. J., 2, 283.

Chesley, L. C., and Annitto, J. E. (1947). Amer. J. Obstet. Gynec., 53, 372. and Jarvis, D. G. (1947). Ibid., 53, 851

d'Abreu, F. (1953). Lancet, 1, 1164

Fishberg, A. M. (1954). Hypertension and Nephritis, 5th ed. London. Morris, N. (1953). Proc. roy. Soc. Med., 46, 402.

Morrow, J. D., Schroeder, H. A., and Perry, H. M. (1953). Circulation, 8, 829.

Newell, J. L., and Smithwick, R. H. (1947). New Engl. J. Med., 236, 851. Northfield, D. W. C. (1948). Proc. roy. Soc. Med., 41, 362.

Peet, M. M. (1948). Amer. J. Surs., 75, 48.

Peet, M. M. (1948), Amer. H. Surs., Pressure. Churchill, London.

Rosenheim. M. L. (1954). Brit. med. J., 2, 1181.

Smirk, F. H. (195\%). Ibid., 1, 717 .

- Doyle, A. E., and McQueen, B. G. (1954). Lancet, 2, 159.

Smithwick, R. H. (1951). J. Amer. med. Ass., 147, 1611

Townsend, L. (1955). J. Obstet. Gynaec. Brit. Emp., 62, 965. 